\title{
Substrate utilization and thermogenic responses to beta-adrenergic stimulation in obese subjects with NIDDM.
}

\author{
Citation for published version (APA):
}

Blaak, E. E., Saris, W. H. M., \& Wolffenbuttel, B. H. R. (1999). Substrate utilization and thermogenic responses to beta-adrenergic stimulation in obese subjects with NIDDM. International Journal of Obesity, 23(4), 411-418. https://doi.org/10.1038/sj.ijo.0800837

\section{Document status and date: \\ Published: 01/01/1999}

DOI:

10.1038/sj.ijo.0800837

\section{Document Version:}

Publisher's PDF, also known as Version of record

\section{Please check the document version of this publication:}

- A submitted manuscript is the version of the article upon submission and before peer-review. There can be important differences between the submitted version and the official published version of record. People interested in the research are advised to contact the author for the final version of the publication, or visit the DOI to the publisher's website.

- The final author version and the galley proof are versions of the publication after peer review.

- The final published version features the final layout of the paper including the volume, issue and page numbers.

Link to publication

\footnotetext{
General rights rights.

- You may freely distribute the URL identifying the publication in the public portal. please follow below link for the End User Agreement:

www.umlib.nl/taverne-license

Take down policy

If you believe that this document breaches copyright please contact us at:

repository@maastrichtuniversity.nl

providing details and we will investigate your claim.
}

Copyright and moral rights for the publications made accessible in the public portal are retained by the authors and/or other copyright owners and it is a condition of accessing publications that users recognise and abide by the legal requirements associated with these

- Users may download and print one copy of any publication from the public portal for the purpose of private study or research.

- You may not further distribute the material or use it for any profit-making activity or commercial gain

If the publication is distributed under the terms of Article $25 \mathrm{fa}$ of the Dutch Copyright Act, indicated by the "Taverne" license above, 


\title{
Substrate utilization and thermogenic responses to $\beta$-adrenergic stimulation in obese subjects with NIDDM
}

\author{
EE Blaak ${ }^{1 *}$, WHM Saris ${ }^{1}$ and BHR Wolffenbuttel ${ }^{2}$ \\ ${ }^{1}$ Department of Human Biology, Maastricht University, Maastricht, The Netherlands and ${ }^{2}$ Department of Endocrinology, University \\ Hospital Maastricht, Maastricht, The Netherlands
}

OBJECTIVE: This study intended to investigate disturbances in $\beta$-adrenergically-mediated substrate utilization and thermogenesis in obese subjects with mild non insulin-dependent diabetes mellitus (NIDDM).

DESIGN: Following a baseline period of $30 \mathrm{~min}$, the $\beta$-agonist isoproterenol (ISO) was administered in increasing doses of 6,12 , and $24 \mathrm{ng} / \mathrm{kgFFM}_{\mathrm{F}} \mathrm{min}$, each dose for $30 \mathrm{~min}$.

SUBJECTS: Nine healthy lean males (CON, $50.6 \pm 2.4 \mathrm{y}$, \% body fat: $16.0 \pm 1.8$ ) and 10 obese subjects with NIDDM $(51.8 \pm 2.4 \mathrm{y}, \%$ body fat $34.1 \pm 1.9)$.

RESULTS: Basal non esterified fatty acid concentrations (NEFA) and basal fat oxidation (absolute or expressed per unit fat free mass, FFM) were significantly higher in NIDDM as compared to CON, whereas basal carbohydrate (CHO) oxidation was significantly lower. The ISO-induced increase in NEFA-concentrations was blunted in NIDDM $(\triangle$ at $24 \mathrm{ng} / \mathrm{kg}_{\mathrm{FFM}}$.min: CON: $717 \pm 59 \mu \mathrm{mol} / \mathrm{I}$ vs NIDDM: $358 \pm 97 \mu \mathrm{mol} / \mathrm{l}, P<0.01$ ). The non-protein respiratory exchange ratio (RER) did not change in NIDDM and significantly decreased in CON during ISO-infusion $(P<0.05)$, reflecting the tendency towards a blunted increase in fat oxidation in NIDDM ( $\triangle$ fat ox at $24 \mathrm{ng}$; CON: $0.025 \pm 0.005 \mathrm{~g} / \mathrm{min} v s \mathrm{NIDDM}$ $0.016 \pm 0.007 \mathrm{~g} / \mathrm{min}$ ). The ISO-induced thermogenic response was comparable in NIDDM and CON (at $24 \mathrm{ng} \%$ increase above baseline: CON: $16.8 \pm 2.2 \%$ vs NIDDM: $14.7 \pm 0.9 \%$ ). At all time points, there were no significant differences in circulating ISO and noradrenaline concentrations. Basal adrenaline (A) concentrations and $A$ concentrations during ISO-infusion were significantly lower in NIDDM (basal A; CON: $64 \pm 15 \mathrm{pg} / \mathrm{ml}$ vs NIDDM: $25 \pm 2 \mathrm{pg} / \mathrm{ml}, P<0.001$ ).

CONCLUSION: There appear to be deviations in $\beta$-adrenoceptor mediated fat utilization and adrenal medulla function in obesity-associated NIDDM. The impairments in sympathetically mediated fat utilization have previously been observed in 'simple' obese subjects, indicating that these disturbances are confined to the obese state per se.

Keywords: $\beta$-adrenergic stimulation; NIDDM; obesity; fat metabolism; thermogenesis; sympathetic nervous system

\section{Introduction}

The development of (abdominal) obesity is strongly linked to the development of non insulin-dependent diabetes mellitus (NIDDM), hypertension and dyslipidaemia. ${ }^{1,2}$ Obesity and obesity-associated NIDDM type 2 diabetes are associated with disturbances in the utilization of fat as a fuel during $\beta$-adrenergic stimulation or catecholamine infusion. ${ }^{3-7}$ Firstly, resistance of lipolysis to sympathetic stimulation has been reported in obese subjects ${ }^{6,7}$ and in subcutaneous adipocytes ('in vitro') of upper-body obese subjects with hypertension, dyslipidaemia and insulin resistance (IR) or mild NIDDM. ${ }^{4}$ Secondly, a diminished catecholamine induced oxidation of fat has been observed in obese subjects, ${ }^{3,5-7}$ which was due to an impaired uptake and utilization of non-esterified fatty acids (NEFA) by skeletal muscle. ${ }^{6,7}$ This diminished utilization of NEFA was proposed to favour fat

*Correspondence: Dr EE Blaak, Dept of Human Biology, Nutrition Research Centre, Maastricht University, PO Box 616, 6200 MD Maastricht, The Netherlands.

Received 6 July 1998; revised 20 November 1998; accepted 2 December 1998 storage over oxidation and so predispose towards obesity. On the other hand, it is suggested that this diminished muscle NEFA uptake may increase the NEFA supply to the liver, thereby promoting a decreased insulin binding to hepatocytes and an increased hepatic VLDL synthesis. Thus, these deviations in sympathetically mediated fat utilization may provide a link between the obese state and the development of IR and NIDDM. For this reason, it is of special interest to obtain more information on possible defects in $\beta$-adrenoceptor mediated fat utilization in obese subjects with mild NIDDM.

So far, most studies have focussed on the thermogenic response to infusion of exogenous catecholamines. It was suggested that a decreased response to stimulation of the sympathetic nervous system via $\beta$ adrenoceptors may be of importance in the impaired diet-induced thermogenesis of obesity. ${ }^{8}$ This may be a factor contributing to a decreased energy cost of weight maintenance and may thereby be of importance in the development and maintenance of excess body weight. Reports on the impaired thermogenesis in obesity are, however, controversial, which may be due to a large heterogeneity in response. ${ }^{4,9}$ The importance of any accompanying diabetes for the thermogenic response to sympathetic stimuli was 
demonstrated in a report showing that obese diabetic women failed to increase their energy expenditure (EE) during mild cold exposure. ${ }^{10} \mathrm{~A}$ diminished sympathetically mediated thermogenesis in obesityassociated NIDDM would correspond to the finding that hyperinsulinaemia results in a decreased adrenaline-induced thermogenesis. ${ }^{11}$ On the other hand, insulin has been suggested to stimulate the sympathetic nervous system and thermogenesis ${ }^{1}$ and IR is a feature of obesity and NIDDM. Hence, an interaction between the degree of IR, sympathetic activity and thermogenesis is possible.

Thus, as indicated above, previous studies in our laboratory showed deviations in $\beta$ adrenergically mediated fat utilization in obese males, ${ }^{6,7}$ whereas $\beta$-adrenoceptor mediated thermogenesis was not significantly different from controls, ${ }^{6}$ due to a large heterogeneity in response in the obese group. ${ }^{9}$ The impairments in fat utilization may be of importance in the etiology of obesity and IR. The present study was designed to investigate whether similar defects in $\beta$ adrenoceptor fat utilization are present in obese subjects with mild NIDDM, by comparing them to a healthy non-obese control group.

\section{Subjects and methods}

The subjects were nine healthy lean males (CON) and 10 obese subjects with NIDDM, of (on average) $2 \mathrm{y}$ and 4 months duration (range $0.5-8 \mathrm{y}$ ). The diabetic subjects were treated with diet alone $(n=3)$ or together with sulphonylurea $(n=7)$. All diabetic subjects had good blood glucose control $\left(\mathrm{HbA}_{1 \mathrm{c}}\right.$ $6.6 \pm 0.3 \%$, range $5.6-8.3 \%$, normal range $4.4-$ $6.2 \%)$. Besides the blood glucose lowering medication, no other medication was used. No subjects had serious health problems, apart from their diabetes. A normal resting electrocardiogram (ECG) and a normal blood pressure (diastolic blood pressure (DBP) $<95 \mathrm{mmHg}$ ) were prerequisites for participation in the study. Subject characteristics are indicated in Table 1. All subjects participated for no more than $3 \mathrm{~h}$ per week in sports, and none had a physically demanding job. The study protocol was reviewed and approved by the Medical Ethical Review Committee

Table 1 Physical characteristics of the subjects

\begin{tabular}{lcc}
\hline & $\begin{array}{c}\text { Control } \\
(\mathrm{n}=9)\end{array}$ & $\begin{array}{c}\text { NIDDM } \\
(\mathrm{n}=10)\end{array}$ \\
\hline Age $(\mathrm{y})$ & $50.6 \pm 2.4$ & $51.8 \pm 2.4$ \\
Weight $(\mathrm{kg})$ & $73.5 \pm 2.3$ & $104.2 \pm 4.7$ \\
Body mass index $\left(\mathrm{kg} / \mathrm{m}^{2}\right)$ & $23.8 \pm 0.6$ & $32.7 \pm 1.2$ \\
\%Body fat & $16.0 \pm 1.8$ & $34.1 \pm 1.9$ \\
Fat mass $(\mathrm{kg})$ & $11.9 \pm 1.5$ & $36.2 \pm 3.5$ \\
Fat-free mass $(\mathrm{kg})$ & $61.6 \pm 1.8$ & $67.9 \pm 1.9$ \\
Waist-to-hip ratio & $0.94 \pm 0.01$ & $1.06 \pm 0.02$ \\
HbA & $5.1 \pm 0.1$ & $6.6 \pm 0.3$ \\
\hline
\end{tabular}

NIDDM = non insulin-dependent diabetes mellitus of Maastricht University, and all subjects provided written consent.

\section{Body composition}

Body weight was determined on an electronic scale. Circumference measurements to the nearest $1 \mathrm{~cm}$ were made with the subject standing upright. Waist circumference was measured, in each subject, midway between the lower rib margin and the iliac crest at the end of a gentle expiration. The hip circumference was determined at the level of the widest circumference over the great trochanters.

Body composition was determined by hydrostatic weighing with simultaneous lung volume measurement (Volugraph 2000, Mijnhardt, The Netherlands). Body composition was calculated according to the formula of Siri. ${ }^{12}$

\section{Isoproterenol (ISO) infusion test}

In the type 2 diabetic NIDDM subjects, medication was stopped two days before the experiment. For the measurement of the $\beta$-adrenergically mediated metabolic responses, subjects fasted from $20.00 \mathrm{~h}$ the evening before, but were allowed to drink water freely. The experiment started at $08.00 \mathrm{~h}$, and subjects came to the laboratory by car or by bus. Room temperature was kept between $23-25^{\circ} \mathrm{C}$. At the start of the experiment, two canullae were inserted in the left and right antecubital veins. The experiment was started $30 \mathrm{~min}$ after the insertion of the canullae. Following a $30 \mathrm{~min}$ baseline measurement, the $\beta$ agonist ISO was intravenously infused in increasing doses of 6,12 and $24 \mathrm{ng} / \mathrm{kgffm}$.min, with each dose administered for $30 \mathrm{~min}$. The dose is related to ISO sulphate, $69 \%$ of which corresponds to ISO free base. Whole body EE was determined by an open-circuit ventilated hood system (Oxycon Beta, Mijnhardt, The Netherlands). During the experiment, heart rate (HR) was recorded continuously by means of a three-lead ECG. When heart rate had increased by $30 \mathrm{bpm}$ or in case of frequent irregularities in ECG, the ISO-infusion was stopped. At the end of each infusion period, venous blood samples were taken for the determination of catecholamines, non-esterified fatty acids, glucose and insulin. For the determination of catecholamines, a blood sample was taken in a heparinized syringe and was put into a glutathione-containing tube on ice.

For the determination of the other metabolites, blood was taken in syringes containing EDTA. The samples were immediately centrifuged at $3000 \mathrm{rpm}$ at $4^{\circ} \mathrm{C}$, and were put into liquid nitrogen and subsequently stored at $-80^{\circ} \mathrm{C}$. Concentration of ISO, noradrenaline (NA) and adrenaline (A) were determined by high-performance liquid chromatography (HPLC) with use of internal standards. ${ }^{13}$ Plasma NEFA and glucose were measured using standard enzymatic techniques automated on the Cobas Bio centrifugal analyzer at $340 \mathrm{~nm}$ (for NEFA: NEFA C, 
Wako Chemicals, Neuss, Germany; for glucose: Roche Diagnostics, Hoffman-La Roche, Basel, Switzerland). Plasma insulin was measured by a specific double antibody radioimmunoassay (RIA) for human insulin (Kabi Pharmacia diagnostics, Uppsala, Sweden). Urine was collected overnight and at the end of the experiment, for the determination of urinary nitrogen, to calculate the nonprotein respiratory exchange ratio, and carbohydrate and fat oxidation (see below).

\section{Calculations}

Gas exchange monitoring.

The metabolic rate was calculated from $\mathrm{VO}_{2}$ and $\dot{\mathrm{V}} \mathrm{CO}_{2}$ according to the equation of Weir. ${ }^{14}$ Carbohydrate $(\mathrm{CHO})$ and fat oxidation rates were calculated from $\mathrm{VO}_{2}$ and $\mathrm{VCO}_{2}$ and urinary nitrogen excretion. The amount of protein oxidized was estimated from total nitrogen excretion, since most of the urinary nitrogen $(>80 \%)$ is in the form of urea, with $1 \mathrm{~g}$ of nitrogen arising from approximately $6.25 \mathrm{~g}$ protein. $\mathrm{CHO}$ and fat (f) oxidation rates were calculated according to the following equations, using values for gas exchange from the table reported by Frayn ${ }^{15}$ :

$$
\begin{aligned}
\mathrm{CHO} & =4.55 \dot{\mathrm{V}} \mathrm{CO}_{2}-3.21 \dot{\mathrm{VO}}_{2}-2.87 \mathrm{n} \\
\mathrm{f} & =1.67 \dot{\mathrm{VO}}_{2}-1.67 \dot{\mathrm{V}} \mathrm{CO}_{2}-1.92 \mathrm{n}
\end{aligned}
$$

$\dot{\mathrm{VO}}_{2}$ and $\dot{\mathrm{VCO}}_{2}$ are in litres per minute, and $\mathrm{n}$ is nitrogen excretion in grams per minute.

\section{Statistics}

Results are presented as means \pm s.e.m. To indicate significant changes in metabolic responses during ISO within groups, a repeated measures analysis of variance was performed. To compare the ISO-induced metabolic responses between groups, a two factor repeated measurements ANOVA was performed. If appropriate, post-hoc testing was undertaken with a Student's unpaired $t$-test. To adjust resting EE for differences in fat free mass (FFM) between groups, an analysis of covariance was used. A $P$-value $<0.05$ was regarded as statistically significant.

\section{Results}

After 10 min of ISO infusion, thermogenic and heart rate responses reached a steady state, that is, $5 \mathrm{~min}$ values remained stable until the end of the experiment (Figure 1, left panel). Therefore, mean values for the

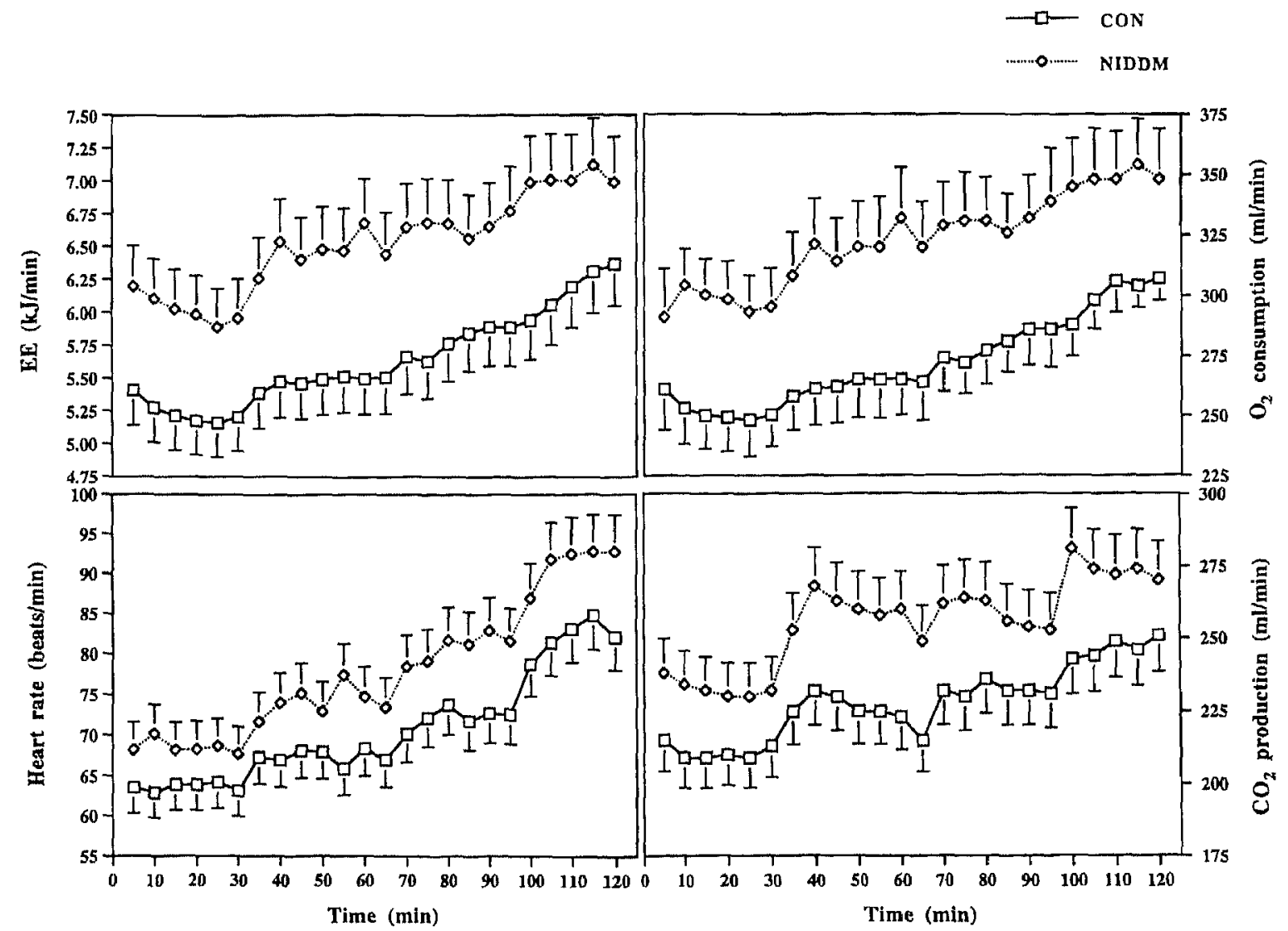

Figure 1 Five-minute values for energy expenditure (EE), heart rate, $\mathrm{O}_{2}$-consumption and $\mathrm{CO}_{2}$ production, during stepwise infusion of increasing doses of the non-selective $\beta$-agonist isoproterenol (ISO). $C O N=$ Control; NIDDM = non insulin-dependent diabetes mellitus. 
last $20 \mathrm{~min}$ were considered representative of the administered dose. Respiratory exchange ratio (RER), oxygen consumption (Figure 1, right panel) and carbondioxide production (Figure 1, right panel) reached a steady state after $20 \mathrm{~min}$ of infusion (see also discussion, second paragraph). Therefore, values for the last $10 \mathrm{~min}$ of infusion were taken as representative of the administered dose.

Figure 2 indicates the changes in plasma concentration of ISO, NA and A during ISO infusion. The increase in plasma ISO during ISO-infusion $(P<0.01)$ tended to be higher in NIDDM, but differences between groups did not reach statistical significance (interaction group-repeated measures, $P=0.10$ ). Basal NA concentrations were not
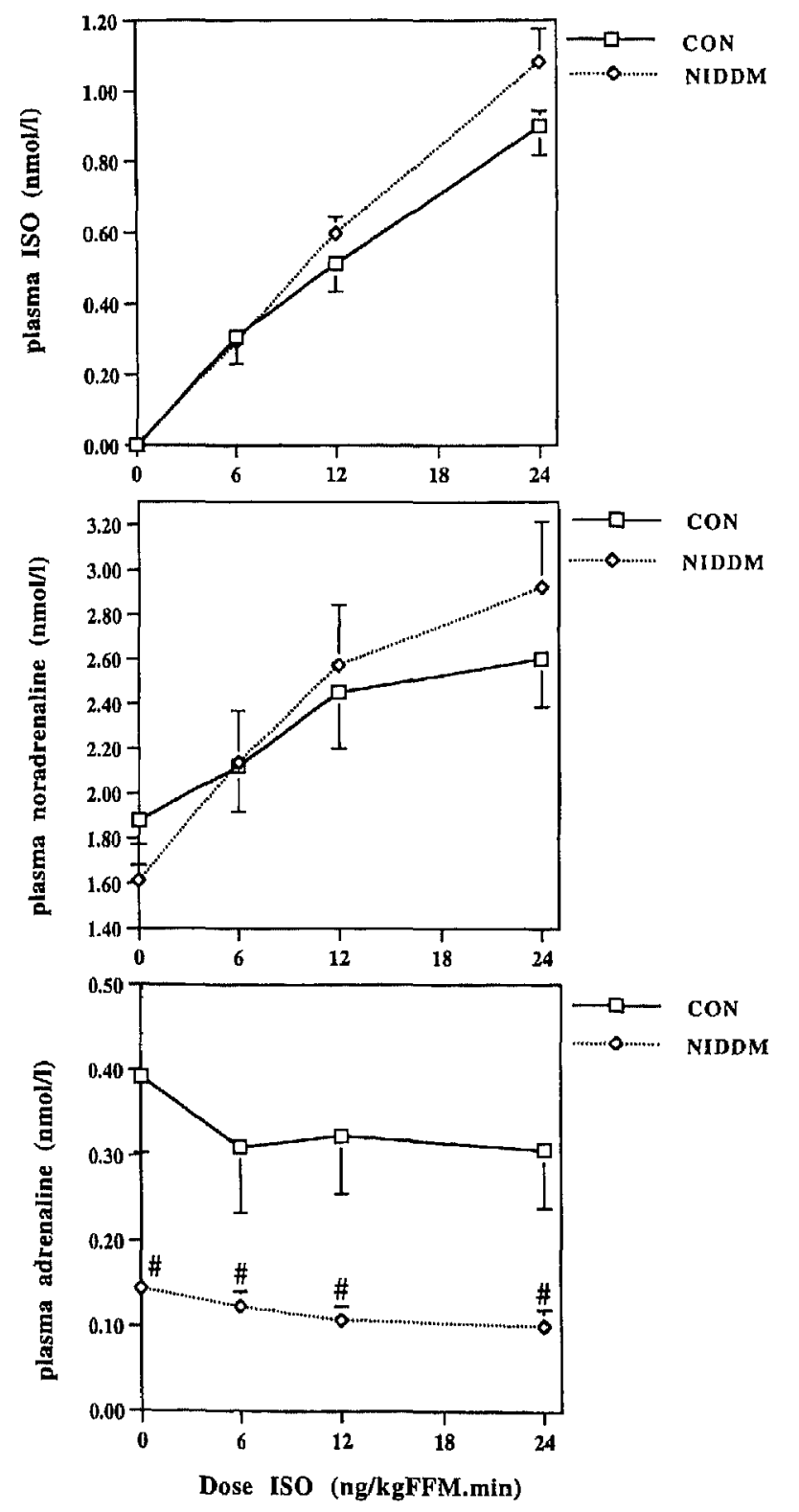

Figure 2 Plasma isoproterenol (ISO), noradrenaline (NA) and adrenaline (A) during stepwise infusion of increasing doses of the non-selective $\beta$-agonist isoproterenol (ISO). $\mathrm{CON}=\mathrm{Control}$; $N I D D M=$ non insulin-dependent diabetes mellitus. $\# P<0.05$ vs CON. significantly different between groups. ISO resulted in a dose-related increase in plasma NA levels in both groups $(P<0.001)$ and this increase was more pronounced in NIDDM as compared to CON (interaction group-repeated measures, $P<0.05$ ). Concentrations of adrenalin were significantly lower in NIDDM as compared to CON during rest and during ISO infusion (effect of NIDDM, $P<0.05$, at all time points $P<0.05$ ). There was a slight decrease in plasma $\mathrm{A}$ in CON $(P<0.05)$, whereas values in NIDDM did not change.

Figure 3 shows values for insulin, glucose and NEFA. In both groups, there was a significant increase in insulin as result of ISO-infusion $(P<0.01)$. Basal insulin concentrations, as well as the ISO-induced
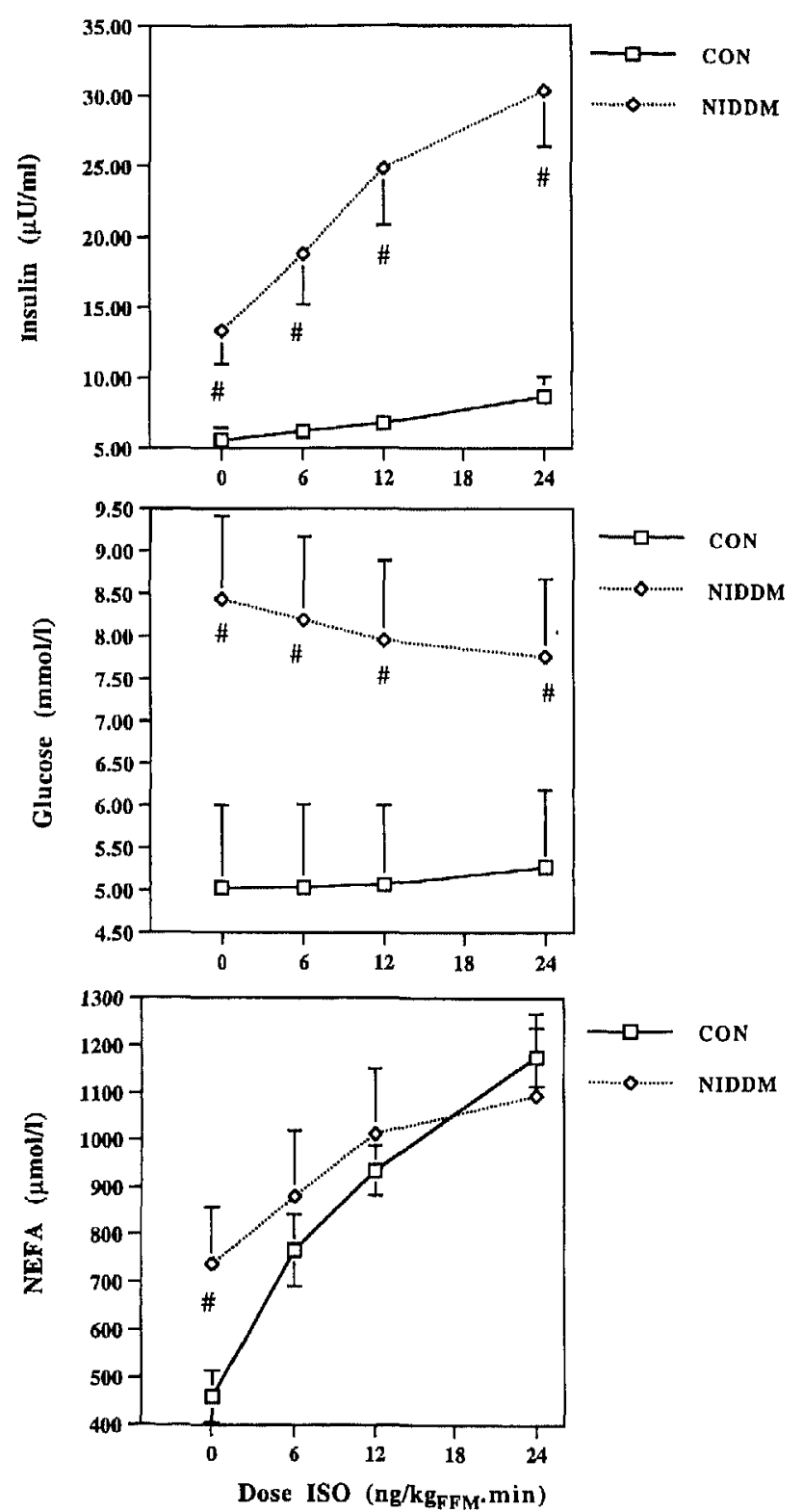

Figure 3 Plasma insulin, glucose and non-esterified fatty acids (NEFA) during stepwise infusion of increasing doses of the nonselective $\beta$-agonist isoproterenol (ISO). \#P $<0.05$ vs CON. 
increase in insulin, were significantly higher in NIDDM compared to CON (effect of NIDDM, $P=0.001$, interaction group-repeated measures, $P<0.001$ ). As expected, glucose concentrations were significantly higher in NIDDM compared to CON, throughout the experiment (effect of NIDDM, $P<0.01$, at all time points $P<0.05$ ). During ISOinfusion, there was a significant decrease of glucose in NIDDM $(P<0.05)$, whereas values did not change in CON. Plasma NEFA concentrations significantly increased during ISO-infusion in both groups $(P<0.001)$. Basal NEFA concentrations were significantly increased in NIDDM $(P<0.05)$, whereas the ISO-induced increase in NEFA concentrations was significantly blunted in NIDDM (interaction grouprepeated measures, $P<0.01$ ), resulting in comparable NEFA concentrations during the ISO-infusion.

Figure 4 represents values for EE, non protein RER and substrate utilization. Resting EE (REE) was significantly higher in NIDDM, compared to CON $(5.96 \pm 0.32 \mathrm{~kJ} / \mathrm{min}$ vs $5.08 \pm 0.24 \mathrm{~kJ} / \mathrm{min}, P<0.01)$, according to the increased FFM in NIDDM. There were no signficant differences in slopes and intercepts for the regression lines of REE vS FFM between both groups, indicating that REE adjusted for FFM is comparable in both groups (ANCOVA, (NS)). The thermogenic response to ISO-infusion was not significantly different between CON and NIDDM, either expressed per kg FFM (Figure 4) or as \% increase above basal (at $24 \mathrm{ng} / \mathrm{kg}$ FFM.min; CON: $16.8 \pm 2.2 \%$ vs NIDDM: $14.7 \pm 0.9 \%, \mathrm{NS}$ ).

The ratio between fat and $\mathrm{CHO}$ oxidation, reflected by the non protein RER, was significantly lower during rest in NIDDM compared to CON (Figure 4, $P<0.05$ ). Non protein RER significantly decreased in CON $(P<0.05)$, whereas in NIDDM, there were no significant differences (Figure 4). At the ISO infusion dose of $6 \mathrm{ng} / \mathrm{kg}$ FFM.min, nonprotein RER was still significantly lower in NIDDM compared to CON $(P<0.05)$, whereas at $12 \mathrm{ng}$ and $24 \mathrm{ng}$ there were no significant differences between groups.

Resting CHO oxidation, either expressed as absolute values (CON: $0.099 \pm 0.02 \mathrm{~g} / \mathrm{min}$ vs NIDDM: $0.053 \pm 0.21 \mathrm{~g} / \mathrm{min}$ ) or per kg FFM (Figure 4), was significantly lower in NIDDM compared to CON $(P<0.05)$, whereas the opposite was seen for basal fat oxidation (CON: $0.056 \pm 0.01 \mathrm{~g} / \mathrm{min}$ vs NIDDM $0.095 \pm 0.01 \mathrm{~g} / \mathrm{min}, P<0.05$, Figure 4 ). CHO oxidation did not significantly change during ISO-infusion in CON, whereas there was a tendency towards an increase in NIDDM $(P=0.055$, Figure 4$)$. At all time points during ISO-infusion, $\mathrm{CHO}$ oxidation, expressed per FFM, was significantly lower in NIDDM as compared to CON $(P<0.05)$. In both groups, there was a significant ISO-induced increase in fat oxidation, whereas this increase tended to be more pronounced in CON $(P<0.001)$ as compared to NIDDM $(P<0.05$, Figure 4$)$. During ISO-infusion, differences
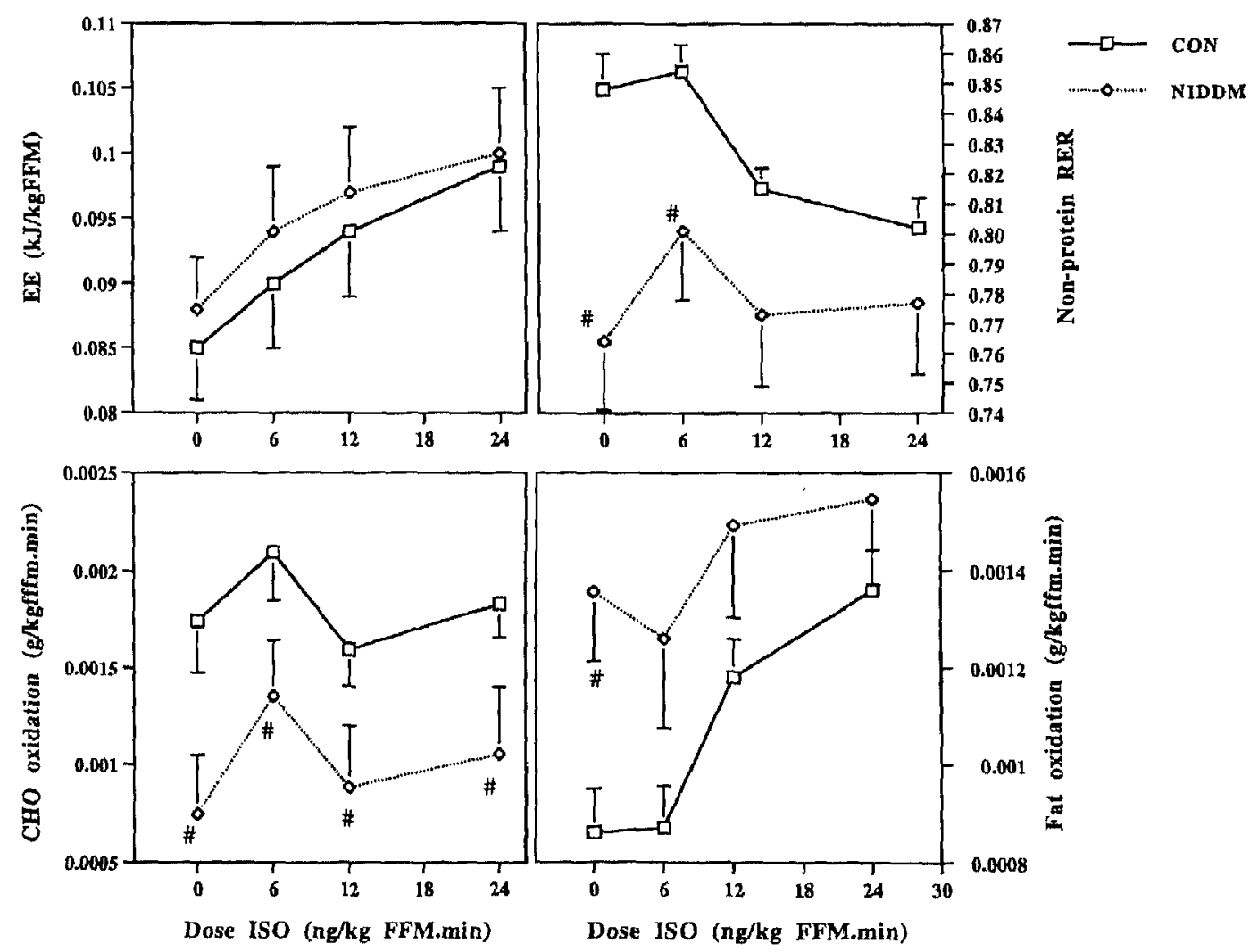

Figure 4 Energy expenditure (EE), non protein respiratory exchange ratio (RER), carbohydrate (CHO) and fat oxidation, during stepwise infusion of increasing doses of the non-selective $\beta$-agonist isoproterenol (ISO). $\# P<0.05$ vs CON. 
in fat oxidation per FFM between CON and NIDDM did not reach statistical significance (Figure 4).

Heart rate significantly increased as result of ISOinfusion in both groups $(P<0.001)$. Resting heart rate (CON:64 $\pm 4 \mathrm{bpm}$ vs NIDDM: $69 \pm 3 \mathrm{bpm}$ ) and the ISO-induced increase in heart rate were not significantly different between groups (at $24 \mathrm{ng}$ CON: $83 \pm 6 \mathrm{bpm} v s$ NIDDM $90 \pm 3 \mathrm{bpm}$ ).

\section{Discussion}

The present study was designed to investigate the sympathetically mediated substrate utilization, thermogenesis and related metabolic responses during $\beta$ adrenergic stimulation in obese subjects with NIDDM. $\beta$-adrenergic responses were evaluated by means of a stepwise infusion of increasing doses of the $\beta$-agonist ISO (each dose for $30 \mathrm{~min}$ ). The major findings of the present study are that during ISOinfusion the increase in circulating NEFA levels is blunted in NIDDM, which is accompanied by a tendency towards a less pronounced ISO-induced increase in fat oxidation. Thus, these data provide some evidence for a diminished $\beta$-adrenergically mediated fat utilization in obesity-associated NIDDM, as reported before in 'simple' obese subjects studied under the same experimental conditions (for data, see Ref 6, Figure 2 and Table 2). These blunted sympathetically mediated responses appear to be of similar magnitude in obese ${ }^{6}$ and obese diabetic subjects (compared to the age-matched control groups), indicating that these impairments may be attributed to the obese state per se. Additionally, at rest and during ISO-infusion, adrenalin concentrations were significantly lowered in obese diabetic subjects, compared to the non-obese control group, whereas in the previous study no differences in adrenalin concentrations could be observed between lean and obese subjects, ${ }^{6}$ suggesting that diminished adrenal medullary function may be related to the diabetic state per se.

Previous research has shown that ISO-infusion steps lasting $8 \mathrm{~min}$ seem representative of steady state responses for ISO-concentrations, plasma NA, heart rate and lipolytic responses. ${ }^{16}$ The present study and previous research ${ }^{6,79}$ have shown representative steady state responses for $\mathrm{EE}$ and heart rate after $10 \mathrm{~min}$ of infusion. Values for $\mathrm{CO}_{2}$ production increased more rapidly than $\mathrm{O}_{2}$ values during the first $10 \mathrm{~min}$ of infusion, resulting in an increase in the RER. This effect was most pronounced during the first ISO infusion dose and is most probably due to hyperventilation ${ }^{17}$ induced via ISO stimulation of central nervous mechanisms. ${ }^{18}$ For this reason, the last $10 \mathrm{~min}$ for the oxygen and carbon dioxide exchanges of each infusion period were taken as the response for the administered doses. ${ }^{9}$
The blunted capacity to increase NEFA concentrations may be explained by an impaired ISO-induced lipolytic response and/or an increased reesterification within adipose tissue or other tissues. Additionally, superficial arm vein blood is derived from deep, as well as superficial, sources, indicating that an increased ISO-induced fractional contribution of blood from subcutaneous adipose tissue in CON may have disturbed the above findings. However, it has previously been shown that the increase in forearm blood flow during ISO-infusion is mainly confined to forearm skeletal muscle. ${ }^{6}$ Secondly, previous data showed that the percentage contribution of forearm subcutaneous adipose tissue blood flow to total blood flow decreases during ISO-infusion in lean subjects (from 19-12\%), whilst no change was observed in obese subjects (11\%, Ref 19$)$, indicating that a greater ISO-induced contribution of subcutaneous adipose tissue blood flow to total blood flow in CON (as compared to the obese diabetic subjects) does not seem very likely. Finally, an impaired catecholamine induced lipolysis has been reported before in obese subjects and 'in vitro' in upper obese subjects with IR and mild NIDDM, ${ }^{5}$ strongly indicating that this impaired lipolysis is an important explanation for the blunted increase in NEFA concentrations in NIDDM.

The observed abnormalities in fat utilization of obese diabetic subjects may favour fat storage over oxidation, and so predispose to obesity and IR. However, the overall importance of these findings in the maintenance of a positive fat balance in NIDDM remains to be determined, since basal circulating NEFA levels and fat oxidation were higher in NIDDM, as reported before, ${ }^{20}$ resulting in comparable NEFA concentrations and slightly, but not significantly, different values for fat oxidation (per FFM) during ISO infusion. The fact that basal NEFA concentrations and fat oxidation are higher in NIDDM does not, however, rule out the possibility that the impaired sympathetically mediated fat utilization has contributed to the development of obesity and IR in NIDDM. Since the diminished sympathetically mediated fat utilization is already present in simple obese subjects, ${ }^{6}$ it can also be speculated that the increased basal lipolysis rate or fat oxidation in NIDDM develops as a compensation for the decreased stimulatory effect of the sympathetic nervous system. Further research is, however, necessary to elucidate the mechanisms and physiological consequences of these deviations in conditions where the energy utilization of the body is increased.

As in the simple obese group, ${ }^{6,7}$ the ISO-induced increase in insulin concentrations was significantly increased in NIDDM, suggesting a possible role of insulin in the diminished increase in NEFA concentrations and the tendency towards a diminished increase in fat oxidation. However, comparable data were reported with adrenalin infusion, where no change was observed in insulin concentrations, ${ }^{3,4}$ 
indicating that insulin is not a major determinant of this diminished increase in fat utilization. As indicated above, in vitro studies showed impaired $\beta_{2}$-adrenergic sensitivity of adipocytes in subjects with upper body obesity and IR or mild NIDDM. ${ }^{5}$ Further in vivo research is necessary to elucidate whether the same mechanisms are operative in vivo and in vitro.

An interaction between degree of IR, sympathetic activity and thermogenesis has been suggested. A blunted thermogenic response to cold exposure has been reported in obese diabetic women, ${ }^{10}$ indicating an impaired sympathetically mediated thermogenesis in NIDDM. The present study showed no evidence for an impaired $\beta$-adrenoceptor stimulated thermogenic response in NIDDM. Also, in the 'simple' obese subjects of the previous study, a normal thermogenic response to ISO-infusion was observed. ${ }^{6}$ Thus, any previously reported blunted thermogenic response to sympathetic stimulation in NIDDM cannot be explained by a decreased $\beta$-adrenergic sensitivity, but may possibly be explained by a decreased NA release by sympathetic nerve endings. Indications in this direction come from a report where a smaller increase in plasma NA, after an oral glucose load, was shown in obese diabetic patients. ${ }^{21}$

Basal sympathetic activity, as reflected by basal plasma NA concentrations, ${ }^{22}$ has been reported to be depressed in diabetic obese patients. ${ }^{21}$ Although plasma NA concentrations were lower in NIDDM compared to $\mathrm{CON}$, this difference did not reach statistical significance. Also, the previous study of obese subjects showed normal plasma NA concentrations. ${ }^{6}$ ISO-infusion increased venous NA concentrations in a dose dependent manner. This has been reported before and is probably due to a counterregulatory vasoconstrictor reflex activated due to ISOinduced vasodilatation. ${ }^{16}$ The ISO induced increase in plasma NA was greater in NIDDM, indicating an increased ISO-induced stimulation of NA release from nerve endings in NIDDM. This finding opens the possibility that an increased ISO-induced sympathetic activation may have interfered with the comparison of $\beta$-adrenergic sensitivity between groups. Although we cannot entirely exclude this possibility, it can be questioned whether thermogenesis and substrate utilization are affected to a great extent by autonomic reflexes. Moreover, differences between groups were probably too small to be of significance.

As indicated above, at rest and during ISO-infusion adrenaline concentrations were significantly lower in obese diabetic subjects compared to CON, which suggests that adrenal medullary function is reduced in NIDDM. No differences in adrenalin concentrations could be observed between lean and obese subjects in the previous study, ${ }^{6}$ suggesting that the lowered venous adrenalin concentrations may be related to the diabetic state per se. Adrenalin deficiency in adrenalin secretion may promote an increase in body fatness per se without necessarily affecting body weight, as discussed elsewhere. ${ }^{23}$ It is tempting to speculate that a deficiency in adrenaline secretion may be involved in the etiology of certain types of obesity, affecting both total body fatness and body fat distribution, which makes these individuals prone to the development of IR and diabetes. In this respect, it is of special interest that in vitro studies showed that the impaired sympathetically mediated lipolysis in obesity and NIDDM are due to a defect in $\beta_{2}$-adrenoceptor sensitivity, for which $A$ is the preferential agonist. However, whether the adrenal medulla plays a role in the regulation of energy metabolism on a daily basis is not yet known. Furthermore, care has to be taken in drawing definite conclusions on basis of forearm superficial venous adrenalin concentrations, since a considerable part of this venous blood may be derived from the forearm muscle and thus may not represent whole body metabolism.

\section{Conclusion}

In summary, the present study shows diminished $\beta$ adrenergically mediated fat utilization and lowered plasma adrenalin concentrations in obese diabetic subjects. The disturbances in sympathetically mediated fat utilization have been observed before in obese subjects. ${ }^{6}$ The present data require further research, especially in view of the increased basal lipolysis and fat oxidation in obesity-associated NIDDM.

\section{Acknowledgements}

This work was supported by a grant from the Dutch Diabetes Foundation.

\section{References}

1 Landsberg L, Krieger KR. Obesity, metabolism and the sympathetic nervous system. Am J Hypertens 1989; 2: $125 \mathrm{~S}-132 \mathrm{~S}$.

2 Björntorp P. Metabolic implications of body fat distribution. Diabetes Care 1991; 14: 1132-1143.

3 Connacher AA, Bennet WM, Jung RT, Bier RM, Smith CCT, Scrimgeour CM, Renie MJ. Effect of adrenaline infusion on fatty acid and glucose turnover in lean and obese human subjects in the postabsorptive and fed states. Clin Sci 1991; 81: $635-644$.

4 Webber J, Taylor J, Greathead H, Dawson J, Buttery PJ, Macdonald IA. A comparison of thermogenic, metabolic and haemodynamic responses to infused adrenaline in lean and obese subjects. Int J Obes 1994; 18: 717-724.

5 Reynisdottir S, Ellerfeldt $\mathrm{K}$, Wahrenberg $\mathrm{H}$, Lithell $\mathrm{H}$, Arner $P$. Multiple lipolysis defects in the insulin resistance (metabolic) syndrome. J Clin Invest 1994; 93: 2590-2599.

6 Blaak EE, van Baak MA, Kemerink GJ, Pakbiers MTW, Heidendal GAK, Saris WHM. $\beta$-adrenergic stimulation of whole body energy expenditure and skeletal muscle metabolism in lean and obese men. Am J Physiol 1994; 267 (Endocrinol Metab 30): E306-E315.

7 Blaak EE, van Baak MA, Kemerink GJ, Pakbiers MTW, Heidendal GAK, Saris WHM. $\beta$ adrenergic stimulation of whole body energy expenditure and skeletal muscle metabolism in relation to weight reduction in obese men. $A m J$ Physiol 1994; 267 (Endocrinol Metab 30): E316-E32. 
8 Shetty PS, Jung RT, James WPT, Barrand MA, Callingham BA. Postprandial thermogenesis in obesity. Clin Sci 1981; 60: $519-525$

9 Blaak EE, van Baak MA, Kester ADM, Saris WHM. Betaadrenergically thermogenic and heart rate response: effect of obesity and weight loss. Metabolism 1995; 44: 520-524.

10 Lean MEJ, Murgatroyd PR, Rothniew I, Reid IW, Harvey R. Metabolic and thyroidal responses to mild cold are abnormal in obese diabetic women. Clin Endocrinol 1988; 28: 665-673.

11 Selberg O, Schlaak S, Balks HJ, von zur Mühlen A, Müller MJ. Thermogenic effect of adrenaline: interaction with insulin. J Appl Physiol 1991; 63: 417-423.

12 Siri WE. The gross composition of the body. Adv Biol Med Physiol 1956; 4: 239-280.

13 Smedes F, Kraak JC, Poppe H. Simple and fast solvent extraction system for selective and quantitative isolation of adrenaline, noradrenaline and dopamine from plasma and urine. $J$ Chromatogr 1982; 231: 25-39.

14 Weir JB. New methods for calculating metabolic rate with special reference to protein metabolism. $J$ Physiol (London) 1949; 109: 1-9.

15 Frayn $\mathrm{KN}$. Calculation of substrate oxidation rates in vivo from gaseous exchange. $J$ Appl Physiol 1983; 55: 628-634.

16 Martinsson A, Lindvall K, Melcher A, Hjehmdahl P: $\beta$ adrenergic receptor responsiveness to isoprenaline in humans: concentration-effect as compared with dose-effect evaluation and influence of autonomic reflexes. Br J Pharmacol 1989; 28: 83-94.
17 Fellows IW, Bennett T, Macdonald IA. The effect of adrenaline upon cardiovascular and metabolic functions in man. Clin Sci 1985; 69: 215-222.

18 Folgering $\mathrm{H}$. Central beta-adrenergic effects on the control of ventilation in rats. Respiration 1980; 39: 131-138.

19 Blaak EE, van Baak MA, Kemerink GJ, Pakbiers MTW, Heidendal GAK, Saris WHM. Total forearm blood flow as indicator of skeletal muscle blood flow, Clin Sci 1994; 87: $559-566$.

20 Felber J, Ferranninni E, Golay A. Role of lipid oxidation in the pathogenesis of insulin resistance and type II diabetes. Diabetes 1987; 36: $1341-1350$.

21 Astrup AV, Christensen NJ, Breum L. Reduced plasma noradrenaline concentrations in simple-obese and diabetic obese patients. Clin Sci 1991; 80: 53-58.

22 Wallin BG, Sundlöf G, Eriksson BM. Plasma noradrenaline correlates to sympathetic muscle nerve activity in normotensive man. Acta Physiol Scand 1981; 111: 69-73.

23 Young JB, Macdonald IA. Sympathoadrenal activity in human obesity: heterogeneity of findings since 1980. Int J Obes 1992; 16: $959-967$. 